\title{
Long term effects of aerosolised rhDNase on pulmonary disease progression in patients with cystic fibrosis
}

\author{
Carlos E Milla
}

\begin{abstract}
Background-After multiple studies, including clinical trials, suggested some mild clinical benefits from the use of rhDNase by patients with cystic fibrosis, a widespread acceptance of the drug has followed. However, long term effects, specifically on lung disease progression, have not been demonstrated. Experience with the use of this drug in a single cystic fibrosis centre is presented and compared with the trends seen in the patient population of the centre before the introduction of the drug.
\end{abstract}

Methods-Patients with cystic fibrosis routinely followed at the University of Minnesota Cystic Fibrosis Center and prescribed rhDNase for at least two years were included in this retrospective study. Data on spirometric parameters $\left(\mathrm{FEV}_{1}\right.$ and FEV $_{1}$ /FVC), allometric index, and admissions to hospital were retrieved from the centre's database for the two years preceding the prescription of rhDNase and the two years that followed. Trends in pulmonary function and allometric index were analysed by mixed linear modelling, and hospital admission rates for both periods were calculated and compared.

Results-One hundred and ninety patients met the inclusion criteria for the study. In the two years preceding the prescription of rhDNase the trends noted were those of a mild decline in $\mathrm{FEV}_{1}$, a stable $\mathrm{FEV}_{1} / \mathrm{FVC}$, and a mild improvement in allometric index. In the two years that followed the prescription of rhDNase a mild decline in all these parameters occurred which was a significant change from the previous period (all $\mathrm{p}<0.009$ ). There was no difference between females and males in the trends experienced after the start of rhDNase. By logistic regression analysis only the presence of malnutrition at the time of prescription was associated with a positive trend after the introduction of rhDNase. No significant change in the hospital admission rates occurred, with rates of $0.52(0.16)$ and $0.56(0.21)$ admissions/patient/year for the periods before and after the prescription of rhDNase, respectively.

Conclusions-The introduction of rhDNase to the regimen of patients with cystic fibrosis cared for at this centre has not been followed by a positive trend in lung function and nutritional parameters. There are some differences between this patient population and those who participated in previous studies which may help to explain the contrasting findings of this study. However, it is also possible that factors other than mucus clearance need to be improved to achieve a favourable response in disease progression. Patients on this treatment should be followed closely and the benefit judged on an individual basis. More studies are needed to define better the specific indications and use of this form of treatment.

(Thorax 1998;53:1014-1017)

Keywords: cystic fibrosis; rhDNase; disease progression

Most of the morbidity and mortality in cystic fibrosis is due to pulmonary complications. Persistent airway inflammation, chronic infection and inspissation of secretions is characteristic of the pulmonary disease, leading to an irreversible and progressive obstructive process. ${ }^{1}$ Typically, bronchial secretions in the presence of infection are tenacious and difficult to clear. Thus, interventions aimed at enhancing clearance of secretions are among the mainstays of therapeutic regimens for patients with cystic fibrosis. ${ }^{2}$

One of the contributory factors to the tenacity of cystic fibrosis secretions is their high content of DNA, a fact recognised during the early investigations into the pathophysiology of cystic fibrosis lung disease. ${ }^{34}$ The efficacy of enzymatic digestion of DNA in altering the viscoelastic properties of purulent respiratory secretions was demonstrated in the early $1950 \mathrm{~s},{ }^{5}$ including studies performed with cystic fibrosis secretions. ${ }^{67}$ Bovine DNase was the enzyme used in these early studies and preparations were available for clinical use as an aerosol. Adverse reactions during aerosol treatment with bovine DNase, ${ }^{8}$ possibly due to the presence of other
Revised manuscript received

Accepted for publication

6 March 1998 
proteins in these preparations, led to the abandonment of this form of treatment. The advent of recombinant DNA technology permitted the successful cloning and production of recombinant human (rh)DNase in $1990 . .^{\circ}$ In vitro studies demonstrated the same efficacy in decreasing sputum viscosity as the early studies with bovine DNase.

During the early 1990s a series of multicentre clinical trials were conducted with the use of aerosolised rhDNase in patients with cystic fibrosis. ${ }^{10}$ These studies showed that the drug was safe in the short term and well tolerated. In addition, patients receiving rhDNase experienced fewer infectious exacerbations requiring admission to hospital. However, only mild clinical effects were noted in terms of pulmonary function and self-reported well being.

To date no study has addressed the issue of the long term efficacy of rhDNase in patients with cystic fibrosis, particularly with respect to the progression of their lung disease. The aim of the present study was to determine whether the introduction of rhDNase to the therapeutic regimen of patients with cystic fibrosis from a large single practice setting has been followed by any detectable changes in the temporal trends in pulmonary function, nutrition, and hospital admission rates. This type of study could provide evidence for the effect of rhDNase on the progression of lung disease in patients with cystic fibrosis.

\section{Methods}

Individuals were selected for the study if they met the following criteria: well documented diagnosis of cystic fibrosis (sweat chloride concentration $>60 \mathrm{mmol} / \mathrm{l}$ or cystic fibrosis genotype testing demonstrating two mutations known to be associated with cystic fibrosis), rhDNase prescribed for daily use at least two years before the study date, and routine follow up for cystic fibrosis care at the University of Minnesota Cystic Fibrosis Center. In addition, pulmonary function testing data had to be available for at least two years before and after the prescription date.

At the University of Minnesota Cystic Fibrosis Center patients are routinely evaluated every three months or sooner when indicated. This evaluation includes spirometric testing, anthropometric measurements, respiratory cultures, and physical examination. According to our treatment protocol, patients are prescribed an intensive daily therapeutic regimen that includes bronchial drainage sessions, aerosolised $\beta_{2}$ agonists and $\mathrm{N}$-acetylcysteine, pancreatic enzyme supplements (except for those who are pancreatic sufficient), multivitamin supplements, and a high caloric content diet. Cultures of respiratory secretions are obtained at each clinic visit and antibiotics prescribed when indicated.

Information on demographic data, pulmonary function test results $\left(\mathrm{FEV}_{1}\right.$ and $\mathrm{FEV}_{1}$ / FVC), nutritional status, respiratory secretion cultures, dates of hospital admissions, and date of start of rhDNase treatment were retrieved from the University of Minnesota Cystic Fibrosis database. Pulmonary function test results were expressed as percentage of the predicted norm for $\mathrm{FEV}_{1}$ and as a percentage for $\mathrm{FEV}_{1} / \mathrm{FVC}$. Nutritional status was assessed by the allometric index (AI), a ratio of weight to predicted weight-for-height based on the data from the National Centre for Health Statistics and expressed as a percentage.

The information was entered with the date on which treatment with rhDNase was started as time 0 so that every individual data point could be identified as having occurred before or after the start of the drug. For each of the outcome variables under study $\left(\mathrm{FEV}_{1}, \mathrm{FEV}_{1} /\right.$ FVC, and AI) a mixed linear regression model was generated so that within and between subject variances could be properly accounted for in the estimation of the slope of the variables of interest over time. The models generated included a spline function that allowed testing for a change in trends between the periods before and after starting treatment with rhDNase.

To account for the possible interactive effects on the trends seen between time and sex, age, or level of $\mathrm{FEV}_{1}$ at the time of prescription, these variables were introduced into the models generated to test for differences between the slopes of their categories. Age was entered as a categorical variable with four age groups defined ( $<10$ years, $10-20$ years, $20-30$ years, and $>30$ years). The level of $\mathrm{FEV}_{1}$ was also entered as a categorical variable with five groups defined according to the percentage predicted $\mathrm{FEV}_{1}(<40 \%, 40-60 \%, 60-80 \%$, $80-100 \%$, and $>100 \%$ ).

All statistical analyses were performed with the SAS for Windows statistical package (Version 6.12, SAS Institute, Cary, North Carolina, USA). An $\alpha$ error level of $5 \%$ was used for statistical significance.

\section{Results}

From the time of the introduction of rhDNase 224 subjects routinely followed at the University of Minnesota Cystic Fibrosis Center were started on the drug at a dose of $2.5 \mathrm{mg}$ aerosolised once a day. This represents $72 \%$ of those eligible to have started the drug in our patient population - that is, those older than five years of age and with a FVC of more than $40 \%$ predicted. The reasons for not starting rhDNase in the remainder of those eligible included the primary pulmonologist's decision, infrequent follow up at the centre, or patient's preference. Of those subjects prescribed rhDNase, only 190 had at least two years of pulmonary function testing data before and after the prescription date and these were included in the study. The characteristics of these subjects at the time of prescription are shown in table $1 ; 103$ were female $(54 \%)$ and 87 were male $(46 \%)$.

Only 17 subjects $(9 \%)$ had an $\mathrm{FEV}_{1}$ below $40 \%$ predicted, $31(16.3 \%)$ had an $\mathrm{FEV}_{1}$ of $40-60 \%$ predicted, $28(14.7 \%)$ of $60-80 \%$ predicted, $46(24.2 \%)$ of $80-100 \%$ predicted, and $68(35.7 \%)$ had an $\mathrm{FEV}_{1}$ of more than $100 \%$ predicted.

During the two year period before the start of rhDNase, 88 subjects $(46.3 \%)$ had experienced a decline in $\mathrm{FEV}_{1}$ and $\mathrm{FEV}_{1} / \mathrm{FVC}, 75$ 
Table 1 Characteristics of the study subjects at the time of rhDNase prescription

\begin{tabular}{llll}
\hline & Mean (SD) & Median & Range \\
\hline Age (years) & $21.04(9.87)$ & 19.67 & $4.95-53.04$ \\
FEV $_{1}(\%$ pred) & $82.89(28.65)$ & 87.30 & $23.22-142.18$ \\
FEV $_{1} /$ FVC (\%) & $0.72(0.16)$ & 0.75 & $0.34-0.99$ \\
AI (\%) & $101.19(16.01)$ & 101.66 & $75.10-153.94$ \\
\hline
\end{tabular}

$\mathrm{FEV}_{1}=$ forced expiratory volume in one second $\mathrm{FVC}=$ forced vital capacity; $\mathrm{AI}=$ allometric index.

Table 2 Slopes of FEV (\% predicted per year) seen in the two years before and the two years after the prescription of rhDNase by age group

\begin{tabular}{lclll}
\hline Age group (years) & $N$ & $\begin{array}{l}\text { Before } \\
\text { rhDNase }\end{array}$ & $\begin{array}{l}\text { After } \\
\text { rhDNase }\end{array}$ & p value \\
\hline$<10$ & 26 & 2.82 & -1.8 & 0.0001 \\
$10-20$ & 81 & -0.25 & -3.09 & 0.0001 \\
$20-30$ & 53 & -0.44 & -3.73 & 0.0002 \\
$>30$ & 30 & -1.29 & -1.56 & 0.78 \\
\hline
\end{tabular}

$\mathrm{p}$ values are for the significance of the change in slope from the pre-therapy period to the therapy period.

subjects (39.4\%) had experienced an improvement in these parameters, and 27 subjects $(14.2 \%)$ had no change in their parameters. Overall, by mixed linear modelling, these 190 patients experienced a mild decline in $\mathrm{FEV}_{1}$ during the two years prior to the prescription of rhDNase (slope $-0.5 \%$ predicted/year). During the previous two year period-that is, four years before the start of rhDNase - the group had also experienced a mild decline in $\mathrm{FEV}_{1}$ (slope $-0.36 \%$ predicted/year). The difference in slopes between the two periods was not significant $(-0.18 \%$ predicted/year, $95 \% \mathrm{CI}-0.61$ to $+0.25, \mathrm{p}=0.4)$.

In the two year period following the introduction of rhDNase the group experienced a decline in $\mathrm{FEV}_{1}$ (slope $-2.62 \%$ predicted/year) which deviated significantly from the trend seen in the previous two year period (difference in slopes $-2.08,95 \%$ CI -1.13 to $-3.03, \mathrm{p}<0.0001)$. When the pulmonary function data for this period were analysed individually for each subject 117 subjects $(61.5 \%)$ experienced no change in their $\mathrm{FEV}_{1}$ trends, 56 subjects $(29.5 \%)$ experienced a decline, and only 17 subjects $(8.9 \%)$ experienced an improvement in $\mathrm{FEV}_{1}$. Of those who experienced a decline in $\mathrm{FEV}_{1}$, in $17(30 \%)$ this was an acceleration of a decline seen in the previous period and in $39(70 \%)$ the decline started after the date of prescription. For the latter group this represented a negative trend seen after a period of improvement or stability in lung function before the start of rhDNase.

There was no significant difference between the trends seen in males and females $(p=0.2)$, with a comparable decline in $\mathrm{FEV}_{1}$ occurring in both groups after the introduction of rhDNase.

Younger individuals (age $<10$ years) had been experiencing a significant improvement in $\mathrm{FEV}_{1}$ before starting treatment with rhDNase. After the introduction of rhDNase all groups experienced a decline in $\mathrm{FEV}_{1}$ with higher rates than those seen in the previous period, except for individuals aged $>30$ years (table 2 ).

When the observed trends were adjusted for level of $\mathrm{FEV}_{1}$ at the time of prescription as an indicator of disease severity, no group experienced a significant improvement. Those indi- viduals whose $\mathrm{FEV}_{1}$ was between $40 \%$ and $60 \%$ predicted continued to decline at a similar rate to that seen before the time of prescription ( $p=0.6$ for difference in slopes). Individuals in other groups experienced a significant acceleration in their rate of decline in $\mathrm{FEV}_{1}$ (all $\mathrm{p}$ $<0.02$ for differences in slopes).

Similar results were observed when either $\mathrm{FEV}_{1} / \mathrm{FVC}$ or $\mathrm{AI}$ was used as the outcome variable. Before the introduction of rhDNase the trend had been for a stable $\mathrm{FEV}_{1} / \mathrm{FVC}$ with a mild decline occurring after its introduction ( $p=0.0001$ for difference in slopes). For AI, after a period of mild improvement, a period of mild worsening followed ( $p=0.009$ for difference in slopes).

In a model simultaneously taking into account the initial age, sex, and level of $\mathrm{FEV}_{1}$ of the subjects, only two specific subgroups were identified as having experienced a change for the better after the introduction of rhDNasewomen aged 20-30 years with an $\mathrm{FEV}_{1}$ of $80-100 \%$ predicted and men aged $>30$ years with an $\mathrm{FEV}_{1}$ of $40-60 \%$ predicted. By logistic regression analysis initial age, sex, absence of Pseudomonas in respiratory secretions, and level of $\mathrm{FEV}_{1}$ were not predictive of a positive trend after the start of rhDNase treatment. However, the presence of malnutrition at the time of prescription, defined as an AI lower than $85 \%$, significantly increased the odds of experiencing a positive trend after the start of rhDNase (odds ratio $6.79,95 \%$ CI 1.41 to 32.78 ).

The number of hospital admissions for pulmonary exacerbations in these 190 patients was also analysed. The annual rates (SE) of hospital admission for these individuals before the start of rhDNase treatment had been stable compared with previous years at $0.52(0.16)$ admissions/patient/year. It remained at the comparable rate of 0.56 (0.21) admissions/ patient/year after the introduction of rhDNase. The number of days spent in the hospital per admission increased slightly, but not significantly, from 6.5 (2.2) days/admission to 7.0 (2.7) days/admission.

\section{Discussion}

The introduction of rhDNase to our practice at the University of Minnesota Cystic Fibrosis Center has not been followed by a positive change in the trends in pulmonary function and nutrition in our patient population. Overall, mild but significant decreases in $\mathrm{FEV}_{1}$, $\mathrm{FEV}_{1} / \mathrm{FVC}$, and $\mathrm{AI}$ have occurred in the group under study after the addition of the drug to their therapeutic regimens.

These findings seem at first to contrast with those from the clinical trials that preceded the introduction of rhDNase ${ }^{11-14}$ and reports on experience with the use of the drug outside clinical trials. ${ }^{15}{ }^{16}$ However, there are a few important differences that need to be mentioned. Firstly, the level of pulmonary function in our patients exposed to rhDNase was considerably better than that seen in all the previously reported studies. In the largest of these studies the mean $\mathrm{FEV}_{1}$ at baseline was around $60 \%$ predicted ${ }^{14}$ which is much lower than that seen in our patient population at the 
start of rhDNase treatment. Secondly, our patients belonged to a single practice setting where one would expect the variability in the standards of care to be lower than in multicentre trials. In a way this introduces some control for the issue of the contributory or derogatory effects that concomitant therapies might have had on the trends seen. Thirdly, the results obtained in our patients reflect the situation outside the rigidity of a clinical trial and under real life conditions where there is less control on the adherence to prescribed therapies.

It is therefore plausible that the patient population in our study is different from the "average" patient in previous studies. In addition, these patients follow an intensive therapeutic regimen, focused on mucus clearance and prevention of pulmonary exacerbations. This may in some way maximise the response to treatment in these patients so that the addition of a new therapy which aims at mucus clearance, such as rhDNase, is of little effect. Alternatively, if the addition of rhDNase did in fact enhance clearance of secretions beyond what the patients' therapeutic regimen was achieving, then the long term effects observed in this group of patients may indicate that enhancing mucus clearance is not the only intervention needed to alter disease progression favourably. A third possibility is that rhDNase may have interacted with other factors involved in lung tissue damage. There is evidence for such a possibility in recent animal studies showing increased neutrophil elastase activity after treatment of cystic fibrosis secretions with rhDNase. ${ }^{17}$

When rhDNase was approved for clinical use there were several questions left unanswered by even the larger studies. ${ }^{18}{ }^{19}$ Its safety was well established and its short term efficacy seemed reasonable, but its long term efficacy and specific indications for its use in patients with cystic fibrosis were not apparent. ${ }^{20}$ This led to a debate about the widespread use of rhDNase in cystic fibrosis with a note of caution being made as to its addition to formularies before more data became available. ${ }^{21}$

rhDNase might be effective for some patients whose characteristics possibly vary from centre to centre and according to the treatment practices in place. Even in those studies that did find, on average, a beneficial effect from treatment with rhDNase, it was noted that not every patient responded favourably and some patients deteriorated. ${ }^{16}$ Because of this, together with the daily cost associated with the drug, patients started on rhDNase ought to be followed closely, both in terms of pulmonary function and frequency of occurrence of pulmonary exacerbations. The benefit from aerosolised rhDNase therapy should be judged on an individual basis and the possibility of an adverse response should be considered if an accelerated worsening in clinical status occurs.

This study was supported in part by a North American Cystic Fibrosis Foundation Center Grant. The author would like to express his gratitude to Drs C Carlyle Clawson, David N Cornfield, Warren E Regelmann, Michael R Shreve, and Warren J Warwick who cared for most of the patients referred to in this study, for their critical review of the manuscript, and their continued support and encouragement.

1 Konstan MW, Berger M. Infection and inflammation of the ung in cystic fibrosis. In: Davis PB, ed. Cystic fibrosis. New York: Marcel Dekker, 1992:219-76.

2 Davis PB, Drumm M, Konstan MW. State of the art: cystic fibrosis. Am f Respir Crit Care Med 1996;154:1229-56.

3 Chernick WS, Barbero GJ. Composition of tracheobronchial secretions in cystic fibrosis of the pancreas and bronchiectasis. Pediatrics 1959;24:739-45.

4 Matthews LW, Spector S, Lemm J, et al. Studies on pulmonary secretions. I. The overall chemical composition of pulmonary secretions from patients with cystic fibrosis, bronchiectasis, and laryngectomy. Am Rev Respir Dis 1963; 88:199-204.

5 Armstrong JB, White JC. Liquefaction of viscous purulent exudates by deoxyribonuclease. Lancet 1950;ii:739.

6 Chernick WS, Barbero GJ, Eichel HJ. In-vitro evaluation of effect of enzymes on tracheobronchial secretions from effect of enzymes on tracheobronchial secretions from
patients with cystic fibrosis. Pediatrics 1961;27:589-96.

7 Lieberman J. Enzymatic dissolution of pulmonary secretions. Am F Dis Child 1962;104:342-8.

tions. Am f Dis Child 1962;104:342-8.
8 Raskin P. Bronchospasm after inhalation of pancreatic dorRaskin P. Bronchospasm after inhalation
nase. Am Rev Respir Dis 1968;98:697-9.

9 Shak S, Capon DJ, Hellmiss R, et al. Recombinant human DNase I reduces the viscosity of cystic fibrosis sputum. Proc Natl Acad Sci USA 1990;87:9188-92.

10 Hodson ME, Shah PL. DNase trials in cystic fibrosis. Eur Respir F 1995;8:1766-91.

11 Hubbard RC, McElvaney NF, Birrer P, et al. A preliminary study of aerosolized recombinant human deoxyribonuclease I in the treatment of cystic fibrosis. N Engl f Med 1992; 326:812-5.

12 Ramsey BW, Astley SJ, Aitken ML, et al. Efficacy and safety of short term administration of aerosolized recombinant human deoxyribonuclease in patients with cystic fibrosis. Am Rev Respir Dis 1993;148:145-51.

13 Ranasinha C, Assoufi B, Shak S, et al. Efficacy and safety of short term administration of aerosolized recombinant human DNase I in adults with stable stage cystic fibrosis. Lancet 1993;342:199-202

14 Fuchs HJ, Borowitz DS, Christiansen DH, et al. Effect of aerosolized recombinant human DNase on exacerbations of respiratory symptoms and on pulmonary fucntion in patients with cystic fibrosis. N Engl f Med 1994;331:63742 .

15 Shah PL, Scott SF, Geddes DM, et al. Two years experience with recombinant human DNase I in the treatment of pulmonary disease in cystic fibrosis. Respir Med 1995;89:499502.

16 Davies J, Trindade MT, Wallis C, et al. Retrospective review of the effects of rhDNase in children with cystic fibrosis. Pediatr Pulmonol 1997;23:243-8.

17 Cantin AM. DNase I acutely increases cystic fibrosis sputum elastase activity and its potential to induce lung sputum elastase activity and its potential to induce lung
hemorrhage in mice. Am $\mathcal{F}$ Respir Crit Care Med 1998;157: 464-9.

18 Range SP, Knox AJ. Editorial: rhDNase in cystic fibrosis. Thorax 1995;50:321-2.

19 Cramer GW, Bosso JA. The role of dornase alfa in the treatment of cystic fibrosis. Ann Pharmacother 1996;30:656-61.

20 Zach MS. The role of recombinant human DNase in the treatment of patients with cystic fibrosis: many promises, more problems. Thorax 1996;51:750-5.

21 Dornase alfa for cystic fibrosis. Drug Ther Bull 1995;33:15-6. 